\title{
A Comparative Study of the Competencies of
}

\section{In-Service Promoted and Directly Selected Elementary} School Teachers Regarding Classroom Management in

\author{
Karak District, Pakistan
}

\author{
Qaiser Suleman \\ M.Phil (Education) Scholar, Institute of Education \& Research, Kohat University of Science \\ \& Technology, Khyber Pakhtunkhwa, (Pakistan) \\ E.mail: Look_for_reality@yahoo.com \\ Dr. Ishtiaq Hussain \\ Assistant Professor, Institute of Education \& Research, Kohat University of Science \& \\ Technology, Khyber Pakhtunkhwa, (Pakistan) \\ E.mail: dr.ishtiaqkust@gmail.com

\section{Muhammad Naeem Butt} \\ Lecturer, Institute of Education \& Research, Kohat University of Science \& Technology, \\ Khyber Pakhtunkhwa, (Pakistan) \\ E.mail:nb840@yahoo.com
}

Accepted: May 17, 2012 Published: December 27, 2012

Doi:10.5296/jsr.v3i2.2984 URL: http://dx.doi.org/10.5296/jsr.v3i2.2984

\begin{abstract}
Classroom management is a critical part of effective and successful instruction. Effective teaching learning process depends upon effective classroom management. Effective classroom management depends upon the competencies of teachers. The purpose of the study was to explore and compare the competencies of in-service promoted and directly selected elementary school teachers regarding classroom management in Karak District (Pakistan). All the students at elementary level in Karak District, Khyber Pakhtunkhwa (Pakistan) constituted the population of the study. In order to ensure adequate representation of population, only 1350 students studying in forty five schools at elementary level in Karak District were selected through simple random sampling technique. From each school, 05 students from class $6^{\text {th }}, 10$ from class $7^{\text {th }}$ and 15 students from $8^{\text {th }}$ were selected. The study was descriptive in nature therefore two similar self-developed structured questionnaires were used for the collection of data. One questionnaire was prepared for in-service promoted elementary school teachers and the other was prepared for directly selected elementary school teachers. Data was collected through personal visits. After the collection of data, it was organized, tabulated, analyzed and interpreted. Percentage and chi-square were used for the statistical treatment of the data. After statistical analysis of data, it was concluded that the
\end{abstract}


overall performance of the directly selected elementary school teachers was highly appreciable. On the other hand, the performance of the in-service promoted elementary school teachers was poor and unsatisfactory. Based on findings, it was strongly recommended that special training should be given to the existing in-service promoted elementary school teachers in classroom management and teaching methodologies to equip them with the modern teaching methods and techniques so that they may perform their duties effectively.

Keywords: Elementary School Teachers, Competencies, Classroom Management, Elementary Level

\section{Introduction}

Classroom management is a critical part of effective and successful instruction. Effective classroom management, which sets in motion with well-organized and efficient lesson planning preparation, assists teacher to teach and students to learn. Students do well in an optimistic classroom atmosphere and an environment in which they feel secure, cared for and involved. From a student point of view, effective and successful classroom management provides students with opportunities to socialize while learning interesting content. From a teacher point of view, effective classroom management involves preventive discipline and interesting instruction (Lang \& Hebert, 1995).

No doubt, that effective and successful teaching learning process depends upon effective classroom management. If a teacher succeeds in making classroom atmosphere favorable for teaching learning process, his productivity as an instructor will be increased. He will be able to communicate his knowledge in a very good way to students and the students will be able to learn efficiently. But unfortunately, our most of the teachers are ignorant about effective classroom management. Even some of them do not know the meaning of classroom management. It is a reality that the quality and competencies of the teachers depend upon the quality of pre-service and in-service teacher's training. Therefore, it can be rightly said that teacher education plays an important and fundamental role in education system, but unfortunately, in Pakistan it has failed to respond to the rapidly changing socio-economic realities. It has also badly failed to improve of the quality of education system. The teachers pass pre-service or in-service courses or get training only for earning a certificate/degree or diploma for increasing their salary and for promotion to higher scale. Therefore teacher education does not emphasis on the required personal and professional competencies and qualities which are required for an effective and successful teacher.

Elementary school teachers are considered the backbone of education system. It is imperative to pay proper attention to strengthen the qualities and competencies of elementary school teachers. That is why it is necessary for the government to ensure the production of competent and qualified elementary school teachers in order to strengthen the elementary education. The paper in hand is written to compare the competencies of the directly selected and in-service promoted elementary school teachers regarding classroom management in District Karak, Khyber Pakhtunkhwa (Pakistan). The same papers will find out the weak and 
strong points of these teachers both directly selected and in-service promoted. In this way the researchers expect that this paper will be highly beneficial and valuable in strengthening the quality of elementary school teachers.

\section{Review of Related Literature}

Competence is a concentric union of an individual's characteristics and behaviours. These characteristics interrelate with and are affected by job demands, organizational environment and professional culture. He considers that the elements of competency are motives, traits, self-esteem, social roles, skills, and knowledge. Each of these characteristics is entailed in the manifestation of any competency behaviour. A competency can generally be evaluated with respect to situational contents, i.e. what one intends to achieve in response to each situation? What action is actually taken? Whether the actions are consistent with intentions? What are the results of one action? (Bibi, 2005).

According to Kalra (1997), competencies can be classified into two broad categories. First type of competencies are those involving the teacher's mental abilities and skills, understanding the principles of psychology and education and his knowledge of the general and specific subject matter to be taught. Second type of competencies is the one stemming from the personality of the teacher, attitudes, beliefs, interests, behaviour and working relationship with pupils and other individuals. Research studies have been conducted by choosing any one or combination of the competencies.

The term "Classroom Management" means, "The art of organizing the class". In other words we can say that classroom management is making the atmosphere and situation of the class as favorable for teaching as to attain the required goals and objectives without any loss of time or energy. It involves proper arrangement of working conditions including light, heat and ventilation (Katozai, 2002). Successful classroom management is defined as producing and ensuring a high rate of work involvement with a low rate of deviancy in academic settings (Laslett \& Smith, 1984). Classroom management is a term used by teachers to explain the process of ensuring that classroom lessons run efficiently in spite of student's disruptive behaviour. The term also means to prevent disruptive behaviour of students. It is perhaps the most difficult aspect of teaching for majority of the teachers; indeed experiencing problems in this area causes some to leave teaching altogether (Online Wikipedia Encyclopedia). According to Dhand (1990), teachers control and manage their instructional effectiveness in the classroom to some considerable degree. The passive teachers only depend upon the same old teaching techniques constantly. On the other hand, the active teachers who change their day planning, various teaching strategies and techniques used for the attainment of more success in teaching. This practice of different teaching techniques not only provides change for the teacher but it also serves as a source of motivation for students.

Good mangers also carefully arrange their classrooms to reduce disturbances and make sure that teaching learning process can proceed efficiently; they arrange their rooms according to the following principles: 
- Teachers should have the ability to observe all students at all times.

- Teaching aids, materials and supplies are readily available.

- High-traffic areas should be free of overcrowding.

- Students should be able to see instructional presentations.

- Procedures and routines should be enthusiastically taught in the same way that academic content is taught (Sadker and Sadker, 1997).

Successful and effective classroom mangers are almost always good planners. They always enter a classroom early to avoid of the likelihood of noise and disturbance created by the students. They are waiting at the door when the children enter into classroom. They take start from the very first day of school and teach the rules about appropriate student's behaviour. They perform this enthusiastically and directly and sometimes they really model the procedures for getting help, leaving the room, going to the pencil sharpener, and the like, the more important rules of classroom behavour are written down, as are the punishments for not following them (Sadker and Sadker, 1997). Once a teacher loses control of their classroom, it becomes increasingly more difficult for them to recover that control (Moskowitz \& Hayman, 1976). Proper arrangement of furniture also plays a vital and crucial role in classroom functioning. Furniture is arranged so that students are familiarized and adjusted to the primary source or sources of information (e.g., the teacher, audio-visual materials), while at the same time having accessibility to other sources are the activities (e.g., work areas, computers) without distressing in the classroom (Nitsaisook and Anderson, 1989).

Best classroom atmosphere is one that results in efficient learning. Discipline involves using guidance and teaching techniques to encourage students to become self-directive and hence to provide an atmosphere favorable and conducive to learning. Sound classroom control is attained most efficiently if teacher is trained and provided with a theoretical and working knowledge of related rules and principles that produce classroom behaviour-principles related to curriculum planning; objectives and procedures; activities and experiences; meaning and behavior; habits; growth and development; environmental effects; adolescent needs and requirements; expectations; readiness and motivation. Only when the teachers have achieved genuine skills in relating such principles to the classroom behaviour of students is they free to concentrate their attention on the other concerns of instruction (Callahan, 1966).

There are various strategies to cope with student misbehavior. Usually, a school has adopted and implemented one approach despite of the approach for handling misbehavior. It is imperative that as a teacher you implant and follow it from the first day of class, whether your students are at the preschool, elementary, or secondary level. It is not so much what you do to stop student's misconduct that characterizes good classroom control but rather how you avoid or stop such misbehavior from occurring in the beginning. A few students are difficult to receive recognition and approval through appropriate behavior at school. Thus these 
students frequently misbehave to get attention, gain control, get revenge, or withdraw from the group. These students in fact have one or more of these goals (Farris, 1996). According to Dhand (1990), for the successful teaching, a teacher must plan successfully. Successful planning means to know how to make easy a positive learning experience for the whole students. For this purpose, the teachers use their best professional decision to choose which methods, strategies and techniques will be beneficial and work best for a particular situation.

According to Sperinthall et al. (1994), teachers communicate expectations to students verbally and non-verbally. It is imperative to be known of the way through which you communicate expectations nonverbally because students' performance is often affected by a teachers subtle, as well as not-so-subtle and blatant approaches. What personal convictions, beliefs or opinions a teacher communicates about the competencies of student has a great effect on the performance of student and sometimes teachers have "reference group" expectations about an entire category or people that can have an effect on all members of that group.

In nutshell, effective classroom management is making the atmosphere and situation of the class as favorable for teaching as to attain the required goals and objectives without any loss of time or energy. The teacher communicates his knowledge in an effective way without any obstruction and the student become able to learn successfully and efficiently. In other words, classroom management is the production and assurance of high rate of work involvement with a low rate of deviancy in academic settings.

\section{Statement of the Problem}

The problem under investigation was specially designed to compare the competencies of directly selected and in-service selected elementary school teachers in classroom management therefore the statement of the problem was entitled " $A$ Comparative Study of the Competencies of In-Service Promoted and Directly Selected Elementary School Teachers Regarding Classroom Management in Karak District, Pakistan”.

\section{Objectives of the Study}

The objectives of the study were:

(a) to compare the competencies of directly selected and in-service promoted elementary school teachers regarding classroom management;

(b) to explore the weak and strong points of directly selected and in-service promoted elementary school teachers regarding classroom management and;

(c) to suggest proper suggestions to improve the quality of elementary school teachers regarding classroom management. 


\section{Research Methodology}

\section{Population of the Study}

All the students at elementary level in Karak District, Khyber Pakhtunkhwa (Pakistan) constituted the population of the study.

\section{Sample \& Sampling Technique}

The researchers selected those schools where both directly selected and in-service promoted elementary school teachers were present. For this purpose, researchers after great effort succeeded in selecting the same schools where both directly selected and in-service promoted elementary school teachers were present. In order to ensure adequate representation of sample, only 1350 students studying in forty five schools at elementary level in District Karak were selected randomly. From each school, 05 students from class $6^{\text {th }}, 10$ students from class $7^{\text {th }}$ and 15 students from $8^{\text {th }}$ were selected. The detail of the sample is given as under:

Table 01: Showing the Size of Sample

\begin{tabular}{cccccccc}
\hline & \multicolumn{3}{c}{ No. of Selected Schools } & \multicolumn{4}{c}{ No. of Students from Each School } \\
\cline { 2 - 8 } Sample & Urban & Rural & Total & From 6 $^{\text {th }}$ & From $^{\text {th }}$ & From 8 $^{\text {th }}$ & Total \\
\hline Size & 15 & 30 & 45 & 05 & 10 & 15 & 30 \\
\hline Total & $\mathbf{1 5}$ & $\mathbf{3 0}$ & $\mathbf{4 5}$ & $\mathbf{2 2 5}$ & $\mathbf{4 5 0}$ & $\mathbf{6 7 5}$ & $\mathbf{1 3 5 0}$ \\
\hline
\end{tabular}

\section{Delimitations of the Study}

The study was delimited to the selected schools in District Karak. The study was further delimited to the male students and teachers.

\section{Research Instrumentation}

The study was descriptive in nature therefore two similar self-developed structured questionnaires were used for the collection of data. One questionnaire was prepared about in-service promoted elementary school teachers and the other was prepared about directly selected elementary school teachers.

\section{Pilot Testing}

Authentic and accurate results of the research study mainly depend upon the authenticity and validity of the research instrument. Therefore pilot testing was conducted to remove the weakness, misconceptions and ambiguities of the questions in questionnaires. After conduction of pilot testing, the questionnaires were revised and then their final versions were prepared.

\section{Validity \& Reliability of the Questionnaire}

It is necessary to ensure the reliability and accuracy of the research instruments. Reliability is the degree of consistency that an instrument or data collection procedure demonstrates, whereas validity is the quality of the collection procedure of the data that enables it to 


\section{Macrothink}

measure what it intends to measure (Gay, 2005; \& Masrur, 2003). Validity of the questionnaires was checked by five experts in the field of education having doctorate degrees. Cronbach's alpha was used to estimate the reliability of questionnaires. The reliability coefficient was found to be 0.81 for both questionnaires. The Cronbach's alpha formula is given as under:

$$
\alpha=\frac{N \cdot \bar{C}}{\bar{V}+(N-1) \cdot \bar{C}}
$$

Where

$$
\begin{aligned}
& \mathrm{N}=\text { Total number of respondents } \\
& \bar{C}=\text { Average inter-item covariance } \\
& \bar{V}=\text { Average variance }
\end{aligned}
$$

\section{Data Collection}

The researchers personally visited to the respective sample students and distributed two two questionnaires among them. First difficult terms were explained and then they were asked to give appropriate responses without any hesitation and free of bias. In this way data was collected about the both directly selected and in-service promoted elementary school teachers.

\section{Data Analysis}

After the collection of data, the data was organized, tabulated and analyzed. Statistical tools i.e., percentage and chi square were used for the statistical analysis of the data. Therefore, percentage and chi square were applied to compare the data. The following formula for chi square was used:

$$
\chi^{2}=\sum \frac{\left[\left(f_{o}-f_{e}\right)^{2}\right]}{f_{e}}
$$

Where

$$
\chi^{2}=\text { Chi-square }
$$

$\sum=$ Sum of

$f_{o}=$ Frequency of occurrence of observed

$\mathrm{f}_{\mathrm{e}}=$ Expected frequency 


\section{Significance of the Study}

The purpose of the study was to explore the competencies of directly selected and in-service promoted elementary school teachers in classroom management and therefore the findings of the study will be beneficial for both in-service promoted and directly selected elementary school teachers as it will explore the weak points of their classroom management and also suggest proper ways and means for the enhancement of their classroom management. In this way they will be able to improve their quality of teaching and classroom management. The researchers also expect that the government will also provide training opportunities for weak in-service elementary school teachers to strengthen their teaching performance and classroom management.

\section{Analysis and Interpretation of Data}

The purpose of the present study was to compare the competencies of directly selected and in-service promoted elementary school teachers in Karak District. Two self-developed structured questionnaires were used as research instrument. Data was collected through personal visits. After collection of data, it was organized, tabulated and analyzed. Simple percentage and chi square were used for the analysis of the data. The whole process is explained as under:

Table 02: At the beginning of the session, your teacher formulates and announces classroom rules and regulations to ensure a favorable environment in side the classroom.

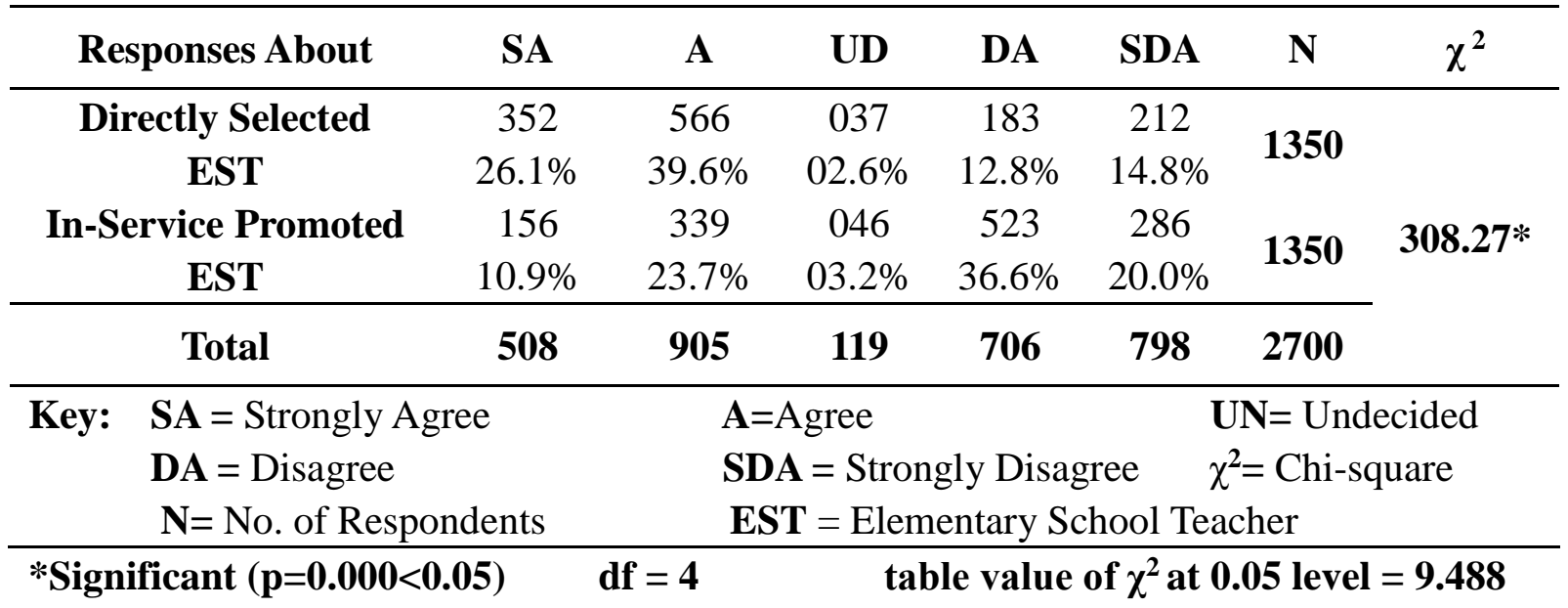




\section{Macrothink}

Journal of Sociological Research

ISSN 1948-5468

2012, Vol. 3, No. 2

Table 2 illustrates that the calculated value of $\chi^{2}$ was found to be 308.27 which is statistically significant $(\mathrm{p}<0.05)$ because it is greater than the table value of $\chi^{2}$ at 0.05 level. It shows that students have different opinions about directly selected and in-service promoted elementary school teachers. They responded that directly selected elementary school teachers formulate and announce classroom rules and regulations to ensure a favorable environment in side the classroom at the beginning of new session whereas in-service promoted elementary school teachers do not formulate and announce the same. It was further clarified by the following bar graph:

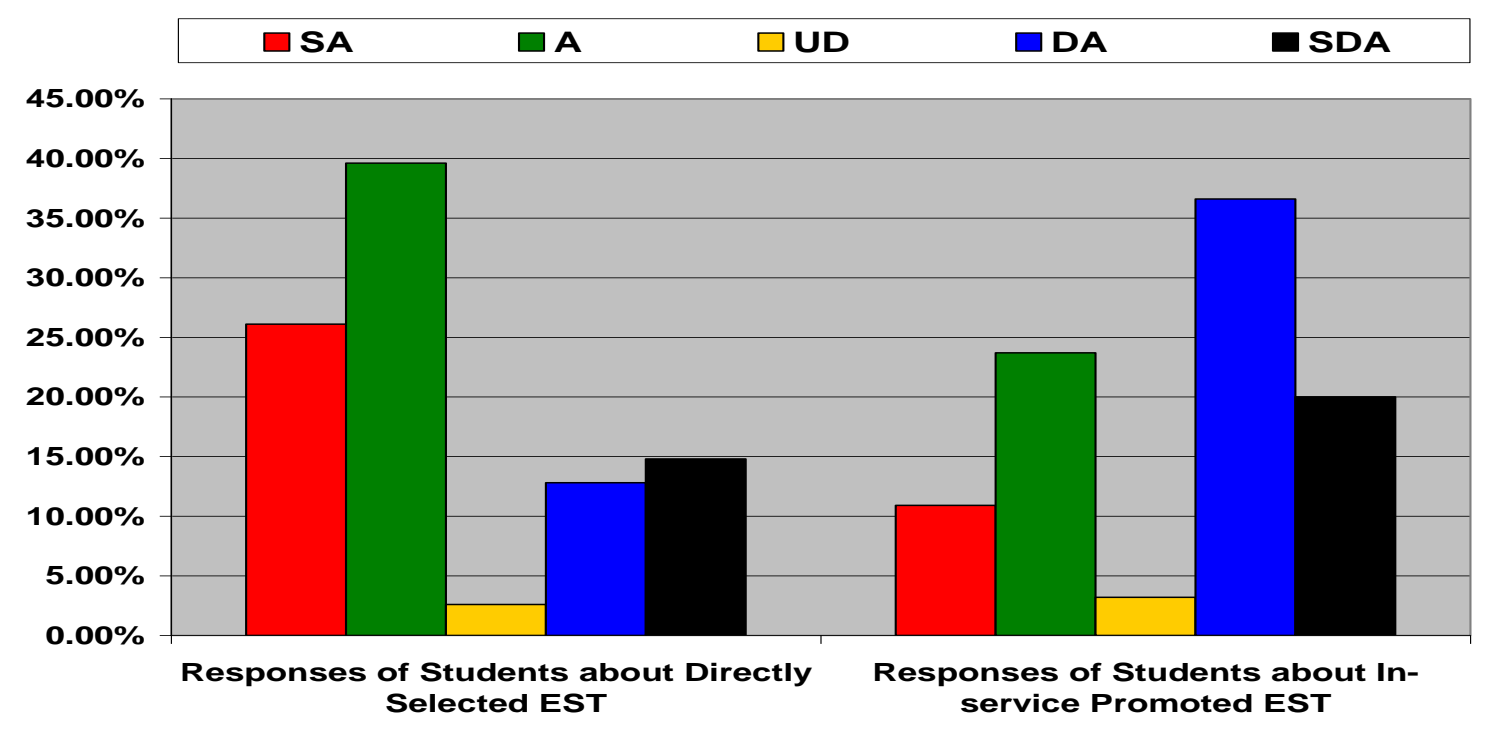

Fig 01: Showing the Responses of Students about In-Service Promoted and Directly Selected Elementary School Teachers

Table 03: Your teacher has the ability to maintain discipline and control disruptive behavior of the students.

\begin{tabular}{|c|c|c|c|c|c|c|c|c|}
\hline & esponses About & SA & $\mathbf{A}$ & UD & DA & SDA & $\mathbf{N}$ & $\chi^{2}$ \\
\hline & irectly Selected & 326 & 596 & 048 & 242 & 138 & \multirow{2}{*}{1350} & \multirow{5}{*}{$230.36 *$} \\
\hline & EST & $22.8 \%$ & $41.7 \%$ & $03.4 \%$ & $16.9 \%$ & $09.7 \%$ & & \\
\hline In-Se & Service Promoted & 213 & 336 & 039 & 427 & 335 & \multirow{2}{*}{1350} & \\
\hline & EST & $14.9 \%$ & $23.5 \%$ & $02.7 \%$ & $29.9 \%$ & $23.5 \%$ & & \\
\hline & Total & 539 & 932 & 87 & 669 & 473 & 2700 & \\
\hline \multirow[t]{3}{*}{ Key: } & \multicolumn{2}{|c|}{$\mathbf{S A}=$ Strongly Agree } & \multicolumn{2}{|c|}{ A=Agree } & & & \multirow{2}{*}{\multicolumn{2}{|c|}{$\mathbf{U N}=$ Undecided }} \\
\hline & \multicolumn{2}{|c|}{$\mathbf{D A}=$ Disagree } & \multicolumn{4}{|c|}{ gree } & & \\
\hline & \multicolumn{2}{|c|}{$\mathbf{N}=$ No. of Respondents } & \multicolumn{5}{|c|}{ EST $=$ Elementary School Teacher } & \\
\hline & icont $(n-000<0$ & & & & & & & \\
\hline
\end{tabular}




\section{Macrothink Institute ${ }^{T M}$}

Table 3 indicates that the calculated value of $\chi^{2}$ was found to be 230.36 which is statistically significant $(\mathrm{p}<0.05)$ because it is greater than the table value of $\chi^{2}$ at 0.05 level. It clearly depicts that students have different views about directly selected and in-service promoted elementary school teachers. They responded that directly selected elementary school teachers have the ability to maintain discipline and control disruptive behavior of the students whereas majority of the in-service promoted elementary school teachers do not maintain discipline and control disruptive behaviour of the students. It was further explained by the following bar graph:

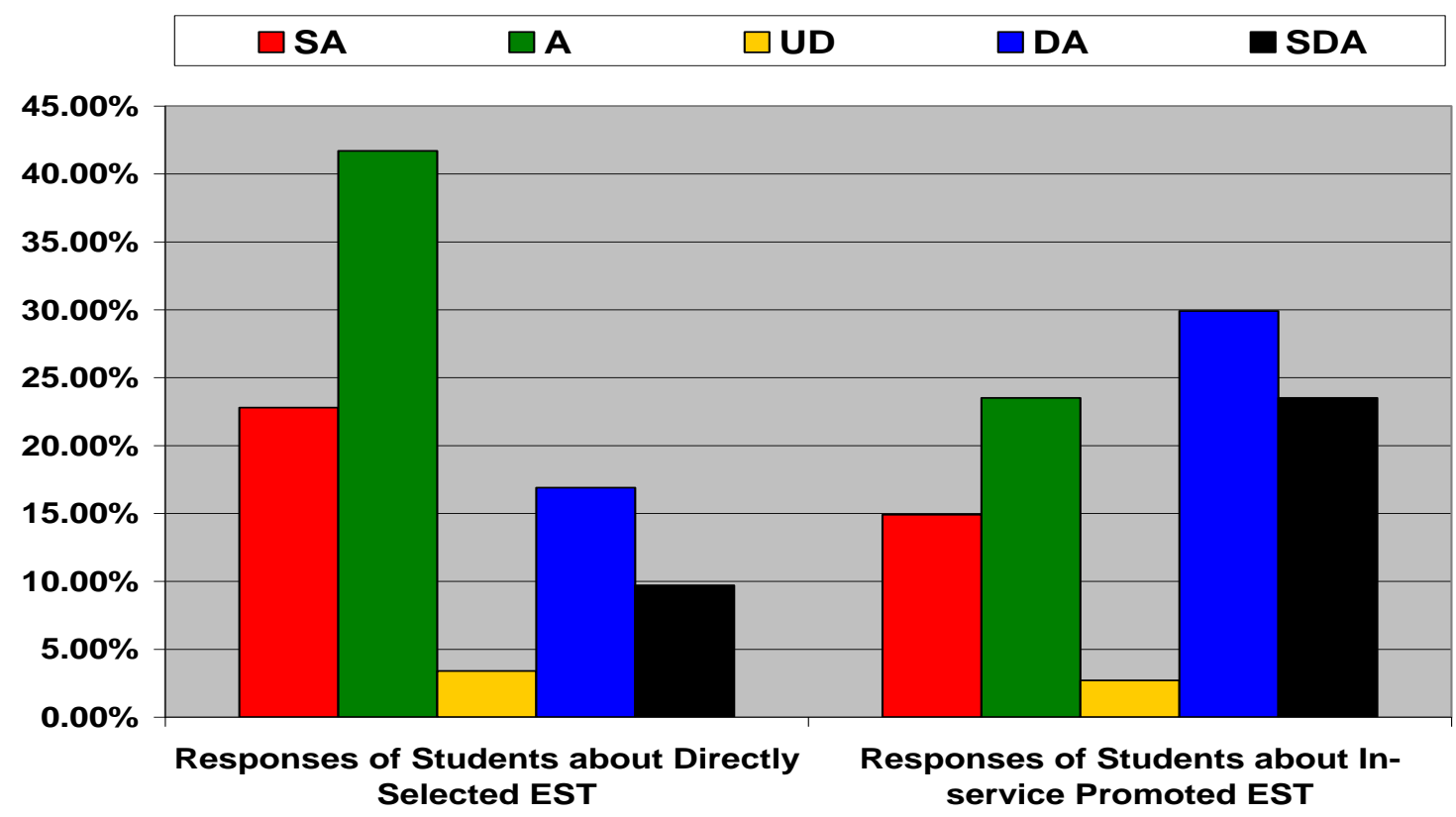

Fig 02: Showing the Responses of Students about In-Service Promoted and Directly Selected Elementary School Teachers

Table 04: Your teacher prevents students from disruptive behavior through moral, religious and motivational lectures.

\begin{tabular}{|c|c|c|c|c|c|c|c|c|}
\hline & sponses About & SA & $\mathbf{A}$ & UD & DA & SDA & $\mathbf{N}$ & $\chi^{2}$ \\
\hline & rectly Selected & 289 & 393 & 064 & 348 & 256 & \multirow{2}{*}{1350} & \multirow{5}{*}{ 253.93* } \\
\hline & EST & $20.2 \%$ & $27.5 \%$ & $04.5 \%$ & $24.4 \%$ & $17.9 \%$ & & \\
\hline In-S & ervice Promoted & 126 & 173 & 056 & 647 & 348 & \multirow{2}{*}{1350} & \\
\hline & EST & $08.8 \%$ & $12.1 \%$ & $03.9 \%$ & $45.3 \%$ & $24.4 \%$ & & \\
\hline & Total & 415 & 566 & 120 & 995 & 604 & 2700 & \\
\hline \multirow[t]{3}{*}{ Key: } & \multicolumn{2}{|c|}{ SA = Strongly Agree } & \multicolumn{2}{|c|}{$\mathbf{A}=$ Agree } & & \multicolumn{3}{|c|}{$\mathbf{U N}=$ Undecided } \\
\hline & \multicolumn{2}{|c|}{ DA = Disagree } & \multirow{2}{*}{\multicolumn{4}{|c|}{ SDA = Strongly Disagree }} & $=$ Chi-s & uare \\
\hline & \multicolumn{2}{|c|}{$\mathbf{N}=$ No. of Respondents } & \multicolumn{4}{|c|}{ EST = Elementary School Teacher } & & \\
\hline
\end{tabular}




\section{Macrothink Institute ${ }^{\mathrm{TM}}$}

Table 4 depicts that the calculated value of $\chi^{2}$ was found to be 253.93 which is statistically significant $(\mathrm{p}<0.05)$ because it is greater than the table value of $\chi^{2}$ at 0.05 level. It shows that students have different opinions about directly selected and in-service promoted elementary school teachers. They responded that majority of the directly selected elementary school teachers prevent students from disruptive behavior through moral, religious and motivational lectures whereas majority of the in-service promoted elementary school teachers do not perform the same. It was further clarified by the following bar graph:

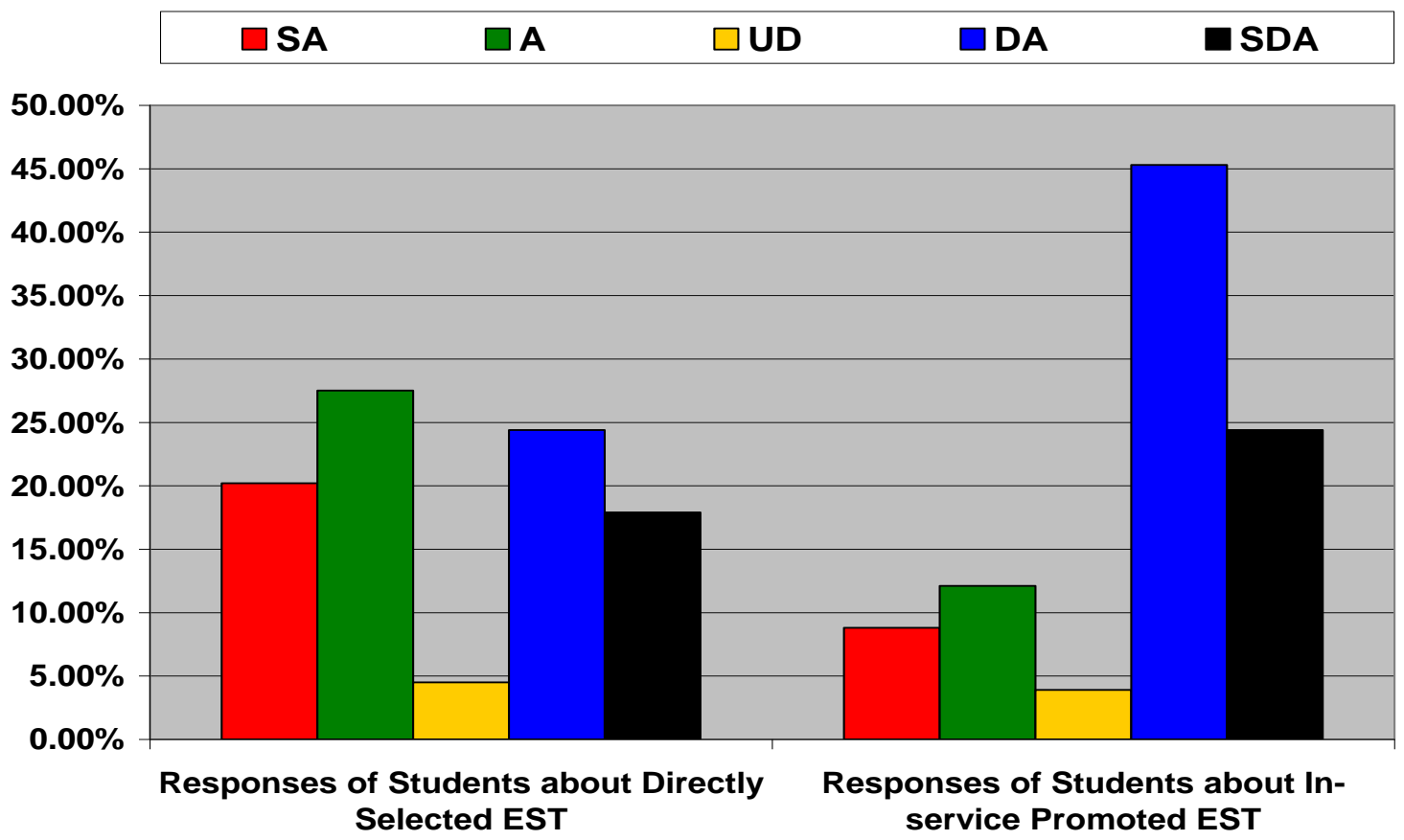

Fig 03: Showing the Responses of Students about In-Service Promoted and Directly Selected Elementary School Teachers

Table 05: Your teacher monitors undesired and offensive activities of the disruptive students constantly and properly.

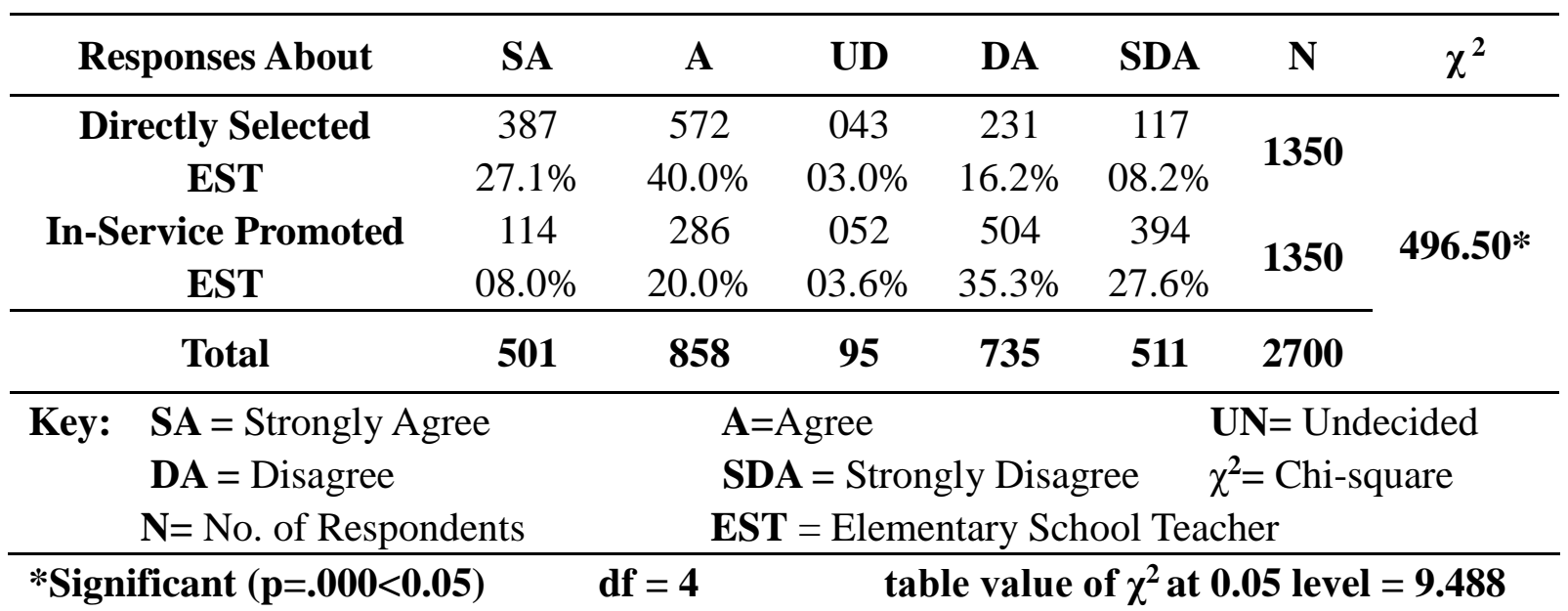




\section{Macrothink Institute ${ }^{\mathrm{TM}}$}

Table 5 shows that the calculated value of $\chi^{2}$ was found to be 496.50 which is statistically significant $(\mathrm{p}<0.05)$ because it is greater than the table value of $\chi^{2}$ at 0.05 level. It clearly indicates that students have different views about directly selected and in-service promoted elementary school teachers. They responded that directly selected elementary school teachers monitor undesired and offensive activities of the disruptive students constantly and properly whereas in-service promoted elementary school teachers do not monitor the same. It was further elaborated by the following bar graph:

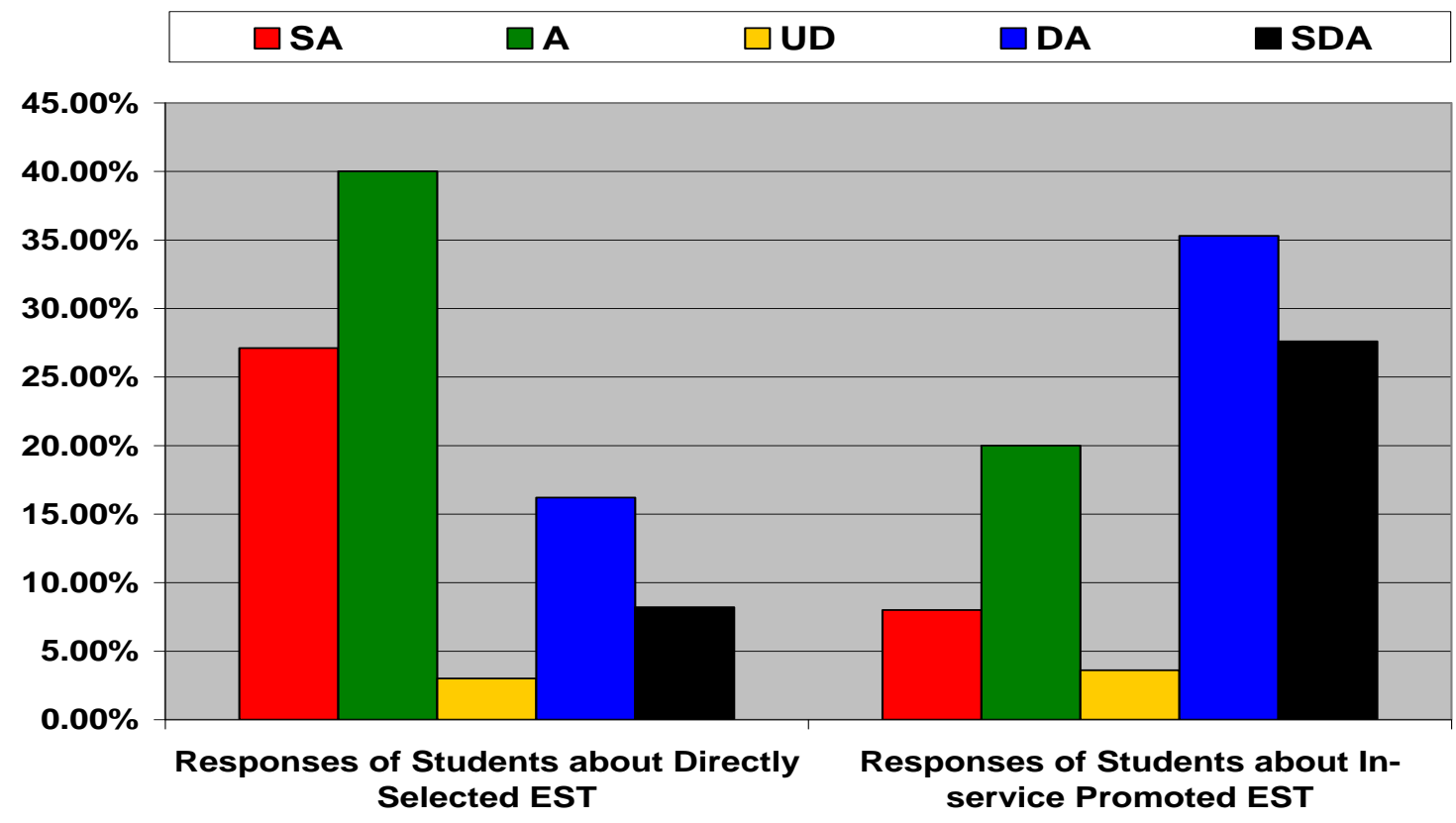

Fig 04: Showing the Responses of Students about In-Service Promoted and Directly Selected Elementary School Teachers

Table 06: Your teacher applies the principles of educational psychology in the classroom.

\begin{tabular}{|c|c|c|c|c|c|c|c|c|}
\hline & sponses About & SA & $\mathbf{A}$ & UD & DA & SDA & $\mathbf{N}$ & $\chi^{2}$ \\
\hline & rectly Selected & 157 & 382 & 062 & 421 & 328 & \multirow{2}{*}{1350} & \multirow{5}{*}{07.87} \\
\hline & EST & $11.0 \%$ & $26.7 \%$ & $04.3 \%$ & $29.5 \%$ & $23.9 \%$ & & \\
\hline In-Se & ervice Promoted & 146 & 359 & 056 & 396 & 392 & \multirow{2}{*}{1350} & \\
\hline & EST & $10.2 \%$ & $25.1 \%$ & $03.9 \%$ & $27.7 \%$ & $27.4 \%$ & & \\
\hline & Total & 303 & 741 & 118 & 817 & 720 & 2700 & \\
\hline \multirow[t]{3}{*}{ Key: } & \multicolumn{2}{|c|}{$\mathbf{S A}=$ Strongly Agree } & \multicolumn{2}{|c|}{$\mathbf{A}=$ Agree } & & & \multicolumn{2}{|c|}{$\mathrm{UN}=$ Undecided } \\
\hline & \multicolumn{2}{|c|}{ DA $=$ Disagree } & \multicolumn{3}{|c|}{ SDA = Strongly Disagr } & ree & $\chi^{2}=$ Chi-s & are \\
\hline & \multicolumn{2}{|c|}{$\mathbf{N}=$ No. of Respondents } & \multicolumn{5}{|c|}{ EST = Elementary School Teacher } & \\
\hline Non-S & Significant $(p=.09$ & $0.05)$ & df $=4$ & & lo & of $\chi^{2}$ at 0 & 0.0210 & \\
\hline
\end{tabular}




\section{Macrothink Institute ${ }^{T M}$}

Table 6 illustrates that the calculated value of $\chi^{2}$ was found to be 07.87 which is statistically non-significant $(\mathrm{p}>0.05)$ because it is less than the table value of $\chi^{2}$ at 0.05 level. It indicates that students have the same opinions about directly selected and in-service promoted elementary school teachers. They responded that both directly selected and in-service promoted elementary school teachers do not apply the principles of educational psychology in the classroom. It was further explained by the following bar graph:

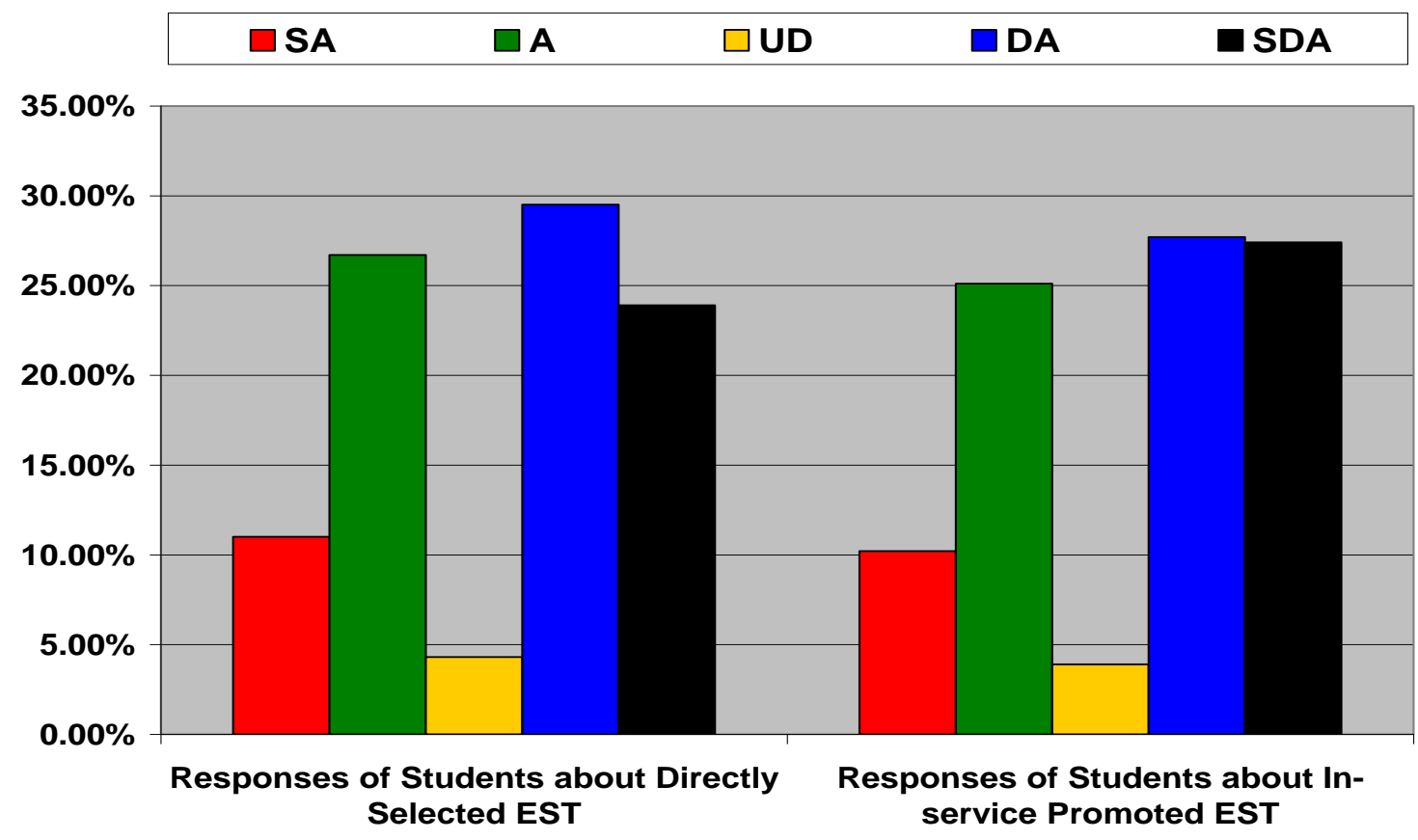

Fig 05: Showing the Responses of Students about In-Service Promoted and Directly Selected Elementary School Teachers

Table 07: Your teacher pays his attention to students individually.

\begin{tabular}{|c|c|c|c|c|c|c|c|c|}
\hline & sponses About & SA & $\mathbf{A}$ & UD & DA & SDA & $\mathbf{N}$ & $\chi^{2}$ \\
\hline & rectly Selected & 294 & 498 & 067 & 278 & 213 & \multirow{2}{*}{1350} & \multirow{5}{*}{$187.93 *$} \\
\hline & EST & $20.6 \%$ & $34.9 \%$ & $04.7 \%$ & $19.5 \%$ & $14.9 \%$ & & \\
\hline In-Se & ervice Promoted & 167 & 283 & 057 & 471 & 372 & \multirow{2}{*}{1350} & \\
\hline & EST & $11.7 \%$ & $19.8 \%$ & $04.0 \%$ & $33.0 \%$ & $26.0 \%$ & & \\
\hline & Total & 461 & 781 & 124 & 749 & 585 & 2700 & \\
\hline Key: & \multicolumn{2}{|c|}{$\begin{array}{l}\text { SA = Strongly Agree } \\
\mathbf{D A}=\text { Disagree } \\
\mathbf{N}=\text { No. of Respondents }\end{array}$} & \multicolumn{4}{|c|}{$\begin{array}{l}\text { SDA = Strongly Disagree } \\
\text { EST = Elementary School Tea }\end{array}$} & \multicolumn{2}{|c|}{$\mathrm{UN}=$ Undecided } \\
\hline \multicolumn{3}{|c|}{ *Significant $(p=.000<0.05)$} & \multicolumn{6}{|c|}{ table value of $\chi^{2}$ at 0.05} \\
\hline
\end{tabular}




\section{Macrothink Institute ${ }^{\mathrm{TM}}$}

Table 7 shows that the calculated value of $\chi^{2}$ was found to be 187.93 which is statistically significant $(\mathrm{p}<0.05)$ because it is greater than the table value of $\chi^{2}$ at 0.05 level. It depicts that students have different opinions about directly selected and in-service promoted elementary school teachers. They responded that majority of the directly selected elementary school teachers pay their attention to students individually whereas majority of the in-service promoted elementary school teachers do not pay their attention to students individually. It was further explained by the following bar graph:

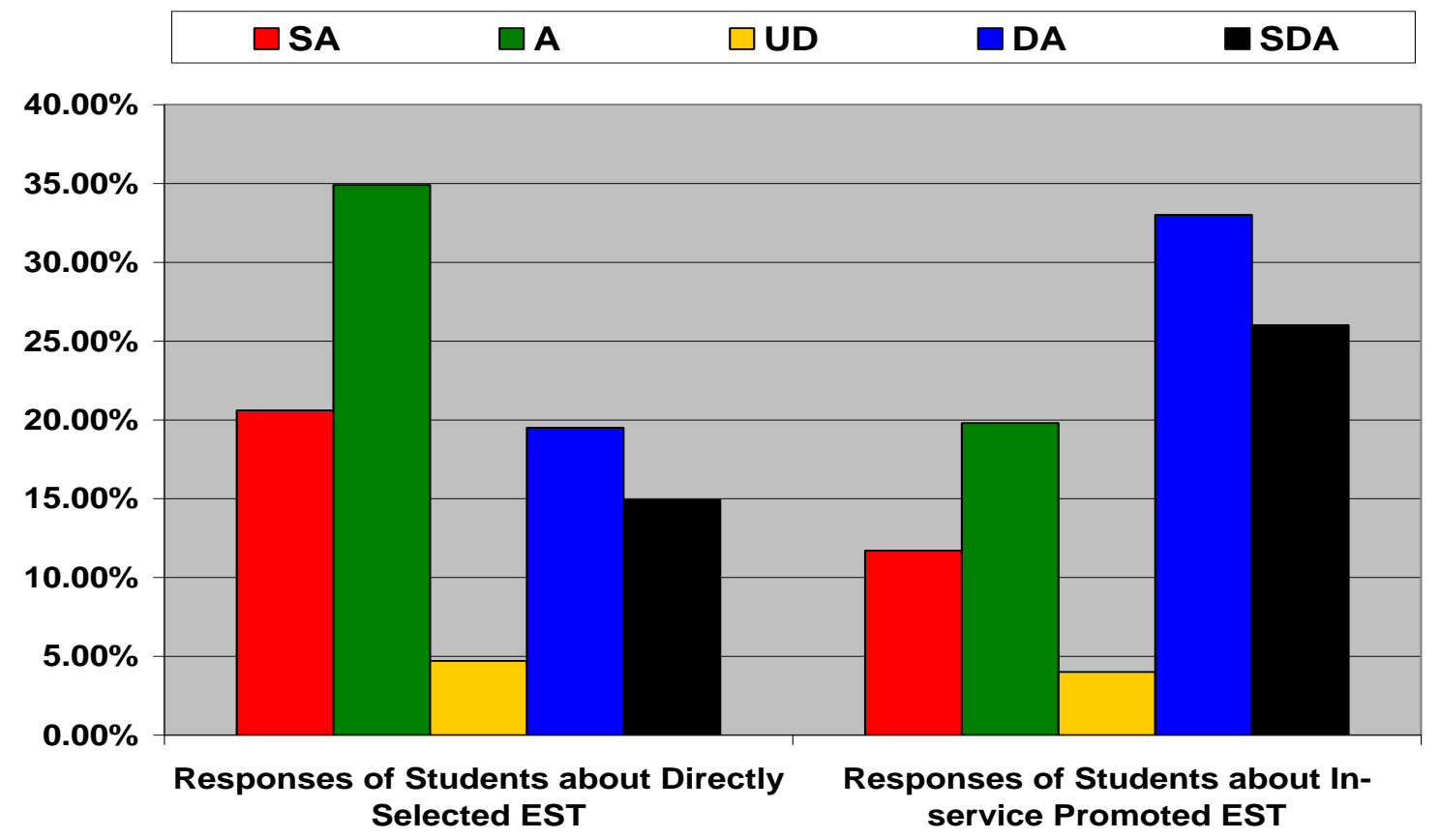

Fig 06: Showing the Responses of Students about In-Service Promoted and Directly Selected Elementary School Teachers

Table 08: Your teacher utilizes educational technologies/Audio visual aids during instructional process.

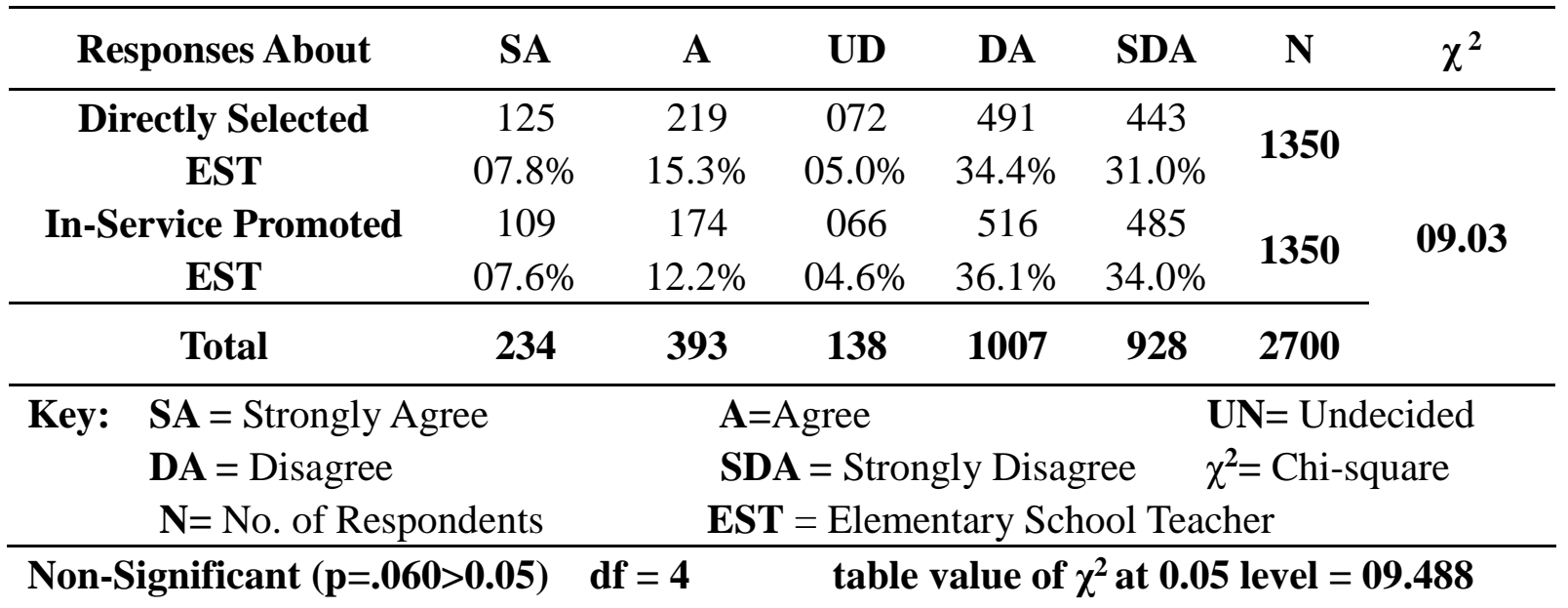


Table 8 indicates that the calculated value of $\chi^{2}$ was found to be 09.03 which is statistically non-significant ( $p>0.05$ ) because it is less than the table value of $\chi^{2}$ at 0.05 level. It shows that students have the same opinions about directly selected and in-service promoted elementary school teachers. They responded that both directly selected and in-service promoted elementary school teachers do not utilize educational technologies/audio visual aids during instructional process. It was further explained by the following bar graph:

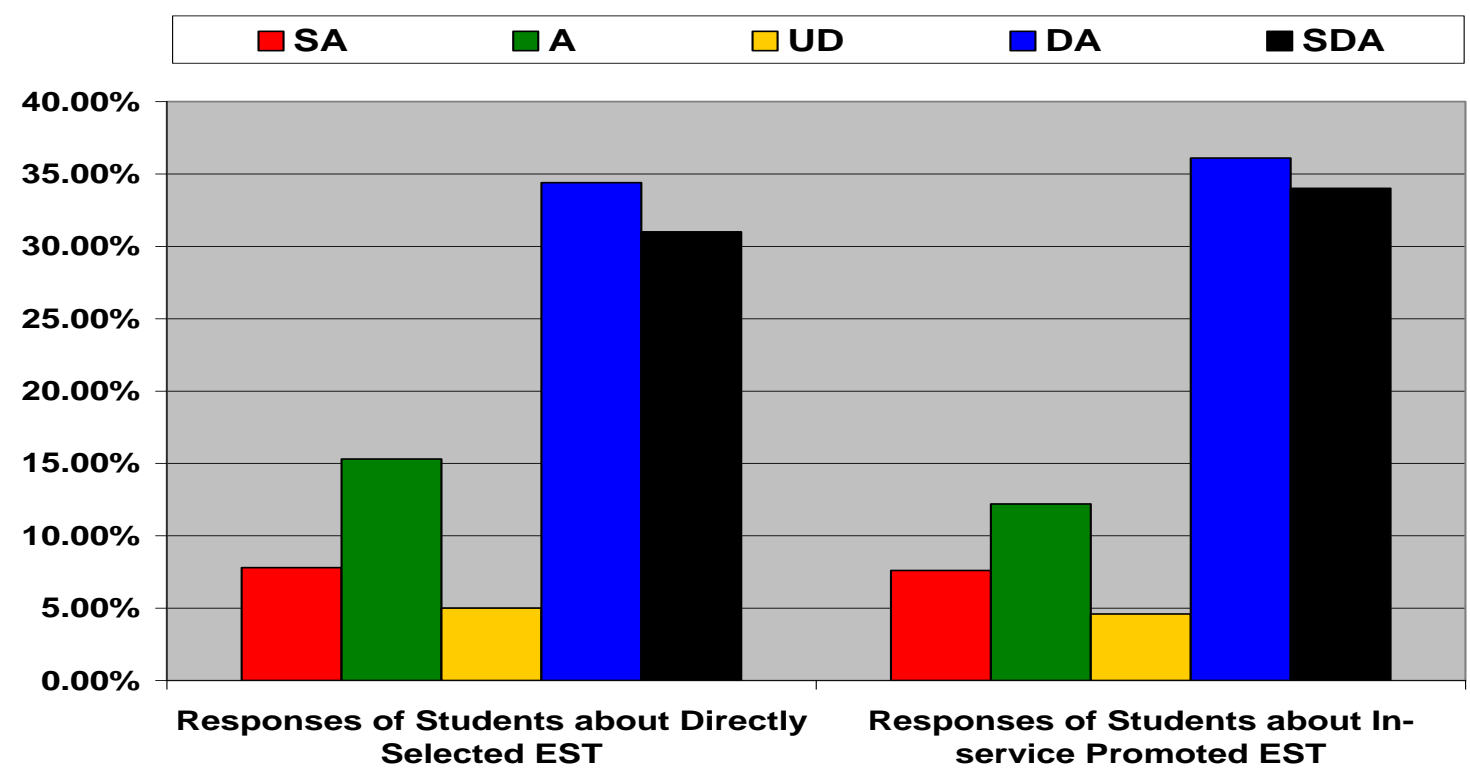

Fig 07: Showing the Responses of Students about In-Service Promoted and Directly Selected Elementary School Teachers

Table 09: Your teacher tries to enhance student's attitudes, behavior, and academic performance.

\begin{tabular}{|c|c|c|c|c|c|c|c|c|}
\hline & sponses About & SA & $\mathbf{A}$ & UD & DA & SDA & $\mathbf{N}$ & $\chi^{2}$ \\
\hline & rectly Selected & 322 & 493 & 058 & 261 & 216 & \multirow{2}{*}{1350} & \multirow{5}{*}{$170.28 *$} \\
\hline & EST & $22.5 \%$ & $34.5 \%$ & $04.1 \%$ & $18.3 \%$ & $15.1 \%$ & & \\
\hline In-S & ervice Promoted & 207 & 276 & 064 & 419 & 384 & \multirow{2}{*}{1350} & \\
\hline & EST & $14.5 \%$ & $19.3 \%$ & $04.5 \%$ & $29.3 \%$ & $26.9 \%$ & & \\
\hline & Total & 529 & 769 & 122 & 680 & 600 & \multirow{2}{*}{\multicolumn{2}{|c|}{$\mathrm{UN}=$ Undecided }} \\
\hline \multirow[t]{3}{*}{ Key: } & \multicolumn{2}{|c|}{$\mathbf{S A}=$ Strongly Agree } & \multicolumn{2}{|c|}{$\mathbf{A}=$ Agree } & & & & \\
\hline & \multicolumn{2}{|c|}{ DA = Disagree } & \multicolumn{4}{|c|}{ SDA = Strongly Disagree } & ${ }^{2}=$ Chi $-\mathrm{s}$ & uare \\
\hline & \multicolumn{2}{|c|}{$\mathbf{N}=$ No. of Respondents } & \multicolumn{5}{|c|}{ EST = Elementary School Teacher } & \\
\hline
\end{tabular}


Table 9 illustrates that the calculated value of $\chi^{2}$ was found to be 170.28 which is statistically significant because it is greater than the table value of $\chi^{2}$ at 0.05 level. It indicates that students have different opinions about directly selected and in-service promoted elementary school teachers. They responded that majority of the directly selected elementary school teachers try to enhance student's attitudes, behavior and academic performance whereas in-service promoted elementary school teachers do not try to enhance student's attitudes, behavior and academic performance. It was further explained by the following bar graph:

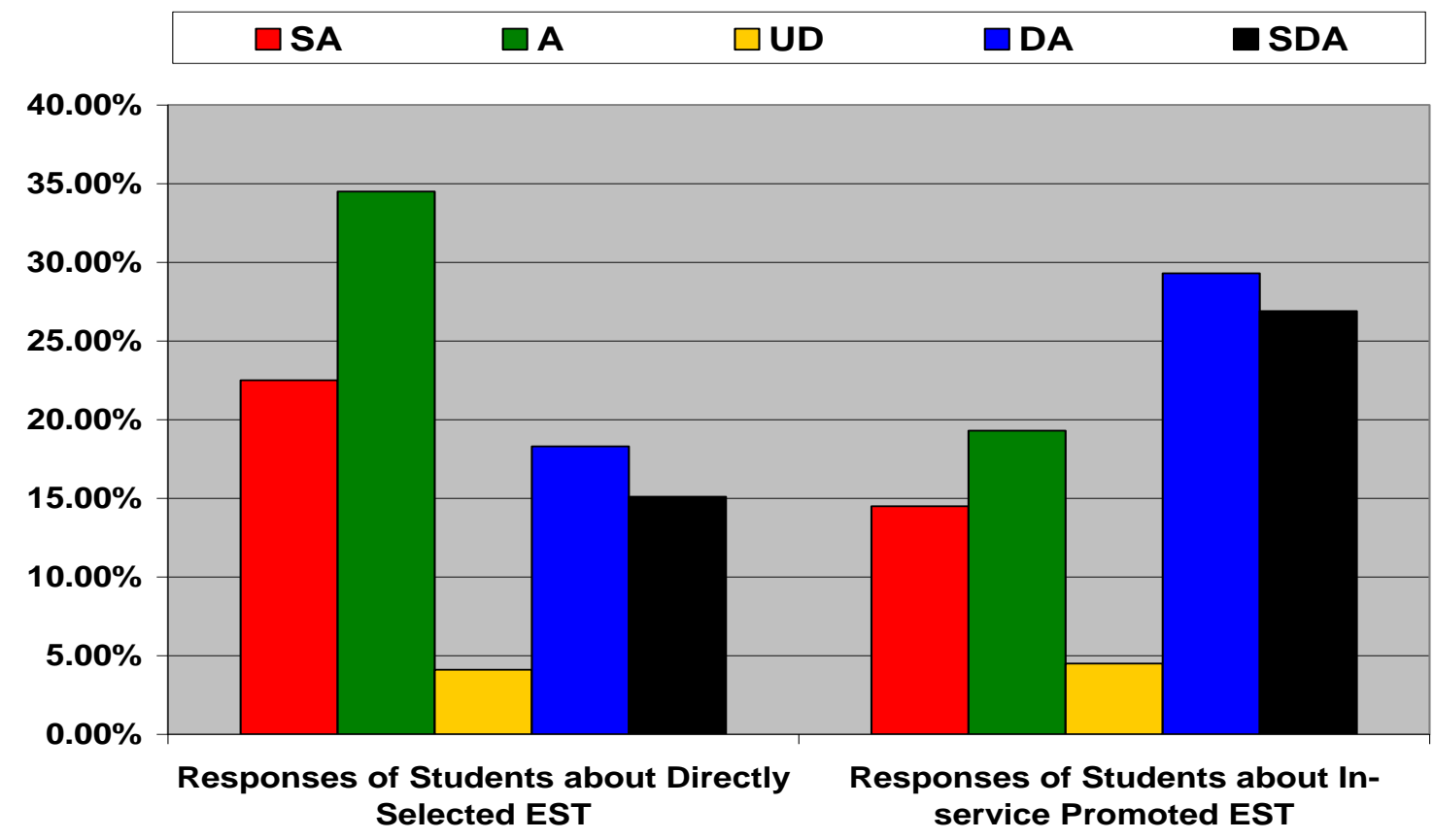

Fig 08: Showing the Responses of Students about In-Service Promoted and Directly Selected Elementary School Teachers

Table 10: Your teacher keeps in mind student's individual differences while teaching in the classroom.

\begin{tabular}{|c|c|c|c|c|c|c|c|c|}
\hline & esponses About & SA & $\mathbf{A}$ & UD & DA & SDA & $\mathbf{N}$ & $\chi^{2}$ \\
\hline & irectly Selected & 266 & 426 & 076 & 349 & 233 & \multirow{2}{*}{1350} & \multirow{5}{*}{$179.73 *$} \\
\hline & EST & $18.6 \%$ & $29.8 \%$ & $05.3 \%$ & $24.4 \%$ & $16.3 \%$ & & \\
\hline In-S & Service Promoted & 148 & 226 & 065 & 463 & 448 & \multirow{2}{*}{1350} & \\
\hline & EST & $10.4 \%$ & $15.8 \%$ & $04.6 \%$ & $32.4 \%$ & $31.4 \%$ & & \\
\hline & Total & 414 & 652 & 141 & 812 & 681 & 2700 & \\
\hline \multirow[t]{3}{*}{ Key: } & \multicolumn{2}{|c|}{$\mathbf{S A}=$ Strongly Agree } & \multicolumn{2}{|c|}{$\mathbf{A}=$ Agree } & & & \multirow{2}{*}{\multicolumn{2}{|c|}{$\begin{array}{l}\mathrm{UN}=\text { Undecided } \\
{ }^{2}=\text { Chi-sgure }\end{array}$}} \\
\hline & \multicolumn{2}{|l|}{ DA = Disagree } & \multicolumn{4}{|c|}{ SDA $=$ Strongly Disagree } & & \\
\hline & \multicolumn{2}{|c|}{$\mathbf{N}=$ No. of Respondents } & \multicolumn{5}{|c|}{ EST $=$ Elementary School Teacher } & \\
\hline
\end{tabular}

*Significant $(p=.000<0.05) \quad$ df $=4 \quad$ table value of $\chi^{2}$ at 0.05 level $=9.488$ 
Table 10 indicates that the calculated value of $\chi^{2}$ was found to be 179.73 which is statistically significant $(\mathrm{p}<0.05)$ because it is greater than the table value of $\chi^{2}$ at 0.05 level. It illustrates that students have different opinions about directly selected and in-service promoted elementary school teachers. They responded that majority of the directly selected elementary school teachers keep in mind student's individual differences while teaching in the classroom whereas majority of the in-service promoted elementary school teachers do not keep in mind student's individual differences during instructional process. It was further explained by the following bar graph:

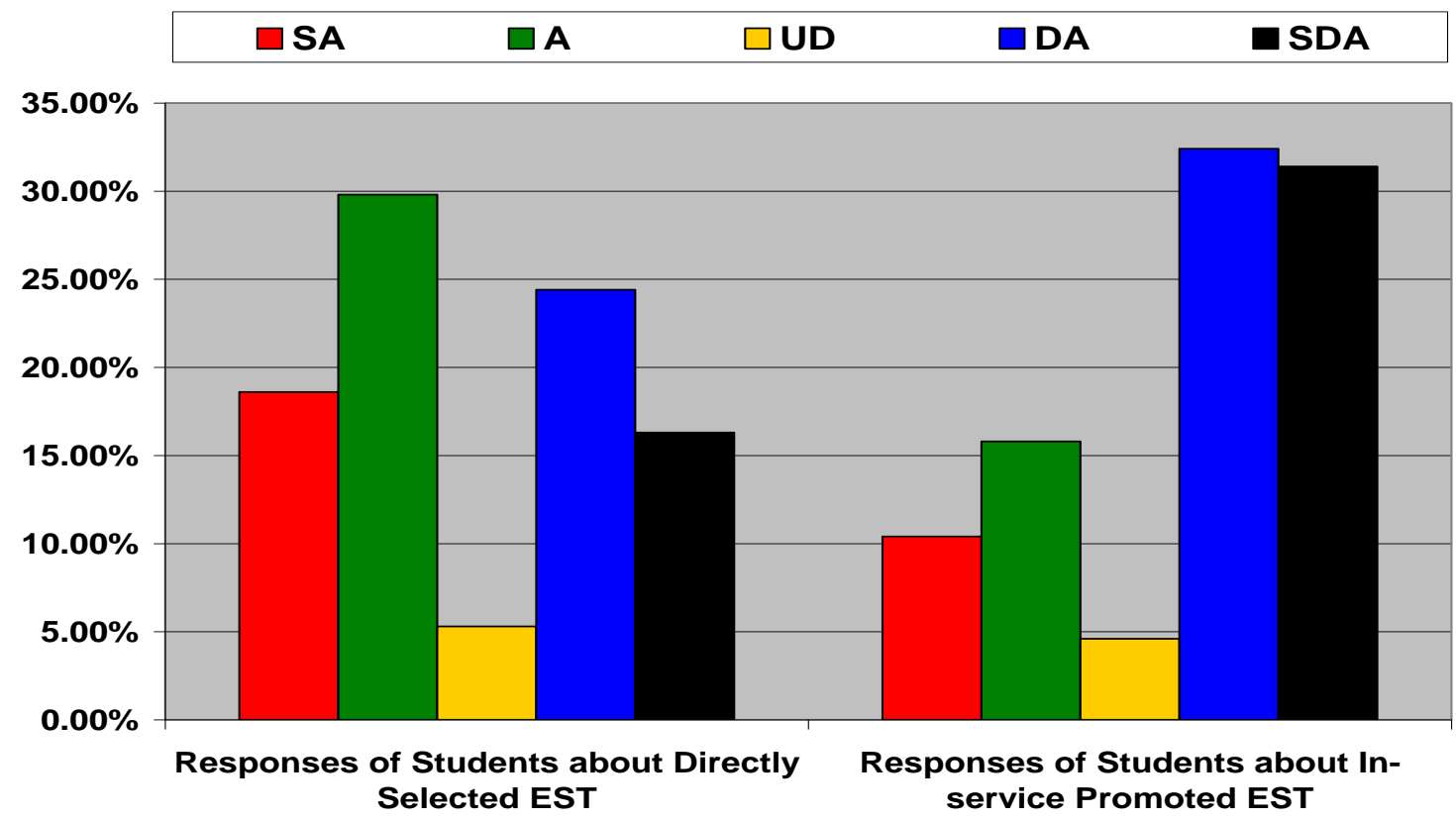

Fig 09: Showing the Responses of Students about In-Service Promoted and Directly Selected Elementary School Teachers

Table 11: Your teacher pays proper attention on cleanliness in the classroom.

\begin{tabular}{|c|c|c|c|c|c|c|c|c|}
\hline $\operatorname{Re}$ & sponses About & $\mathbf{S A}$ & $\mathbf{A}$ & UD & DA & SDA & $\mathbf{N}$ & $\chi^{2}$ \\
\hline Dir & rectly Selected & 395 & 457 & 082 & 279 & 137 & \multirow{2}{*}{1350} & \multirow{5}{*}{ 133.04" } \\
\hline & EST & $27.7 \%$ & $32.0 \%$ & $05.7 \%$ & $19.5 \%$ & $09.6 \%$ & & \\
\hline In-Se & ervice Promoted & 261 & 329 & 077 & 362 & 321 & \multirow{2}{*}{1350} & \\
\hline & EST & $18.3 \%$ & $23.0 \%$ & $05.4 \%$ & $25.3 \%$ & $22.5 \%$ & & \\
\hline & Total & 656 & 786 & 159 & 641 & 458 & 2700 & \\
\hline Key: & $\begin{array}{l}\text { SA }=\text { Strongly } \\
\mathbf{D A}=\text { Disagree } \\
\mathbf{N}=\text { No. of Resp }\end{array}$ & dents & $\begin{array}{r}\mathbf{A}= \\
\text { SI } \\
\text { ES }\end{array}$ & $\begin{array}{l}\text { Agree } \\
=\text { Stror } \\
=\text { Elem }\end{array}$ & $\begin{array}{l}\text { gly Disa } \\
\text { tary Scl }\end{array}$ & $\begin{array}{ll} & \text { I } \\
\text { ree } & \chi \\
\text { ool Teac }\end{array}$ & \multicolumn{2}{|c|}{$\begin{array}{l}\mathbf{U N}=\text { Undecided } \\
y^{2}=\text { Chi-square }\end{array}$} \\
\hline
\end{tabular}




\section{Macrothink Institute ${ }^{T M}$}

Table 11 illustrates that the calculated value of $\chi^{2}$ was found to be 133.04 which is statistically significant $(\mathrm{p}<0.05)$ because it is greater than the table value of $\chi^{2}$ at 0.05 level. It clearly indicates that students have different views about directly selected and in-service promoted elementary school teachers. They responded that majority of the directly selected elementary school teachers pay proper attention on cleanliness in the classroom whereas in-service promoted elementary school teachers do not pay their attention on cleanliness in the classroom. It was further explained by the following bar graph:

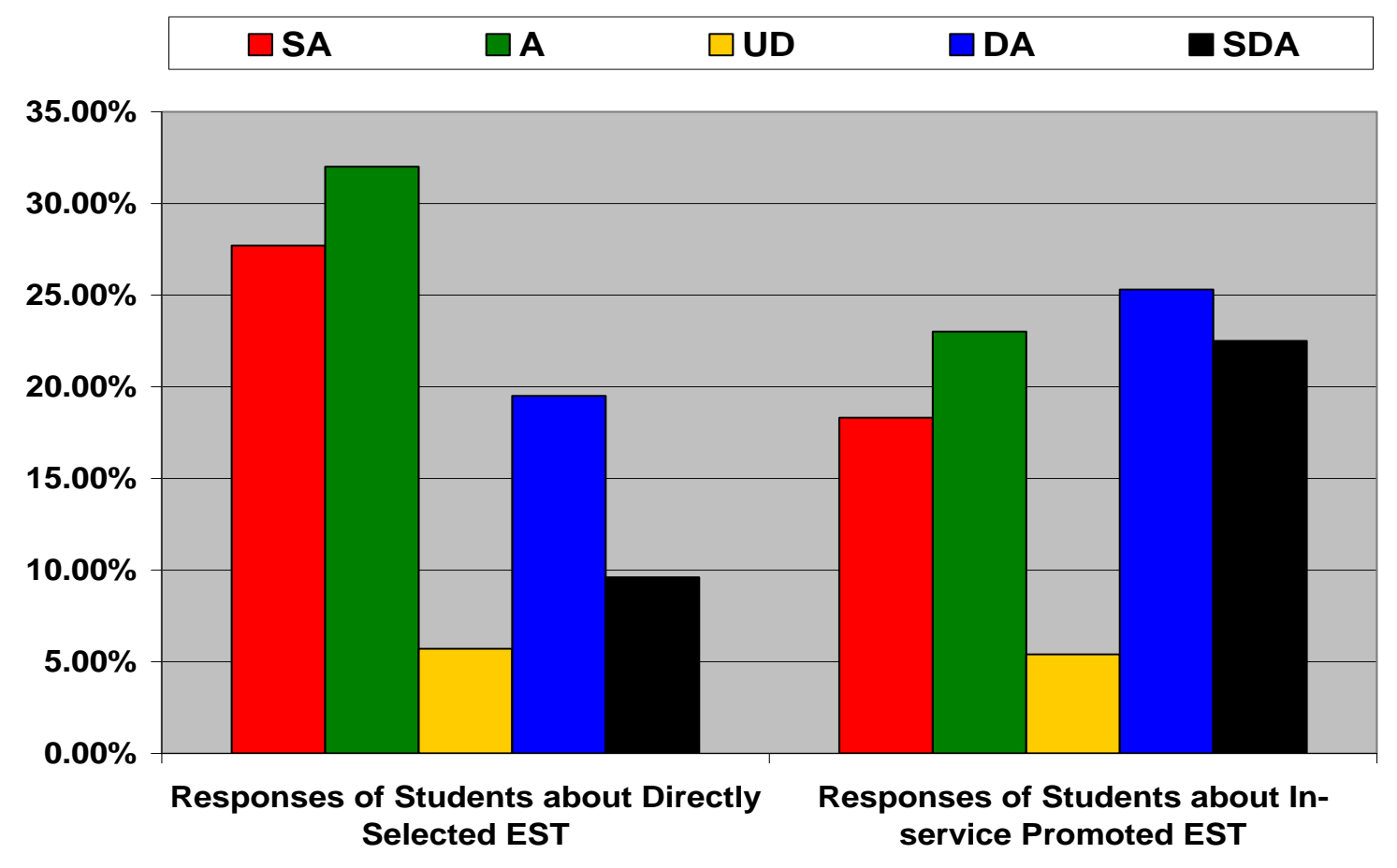

Fig 10: Showing the Responses of Students about In-Service Promoted and Directly Selected Elementary School Teachers

Table 12: Your teacher has the ability to manage student's seating arrangement properly.

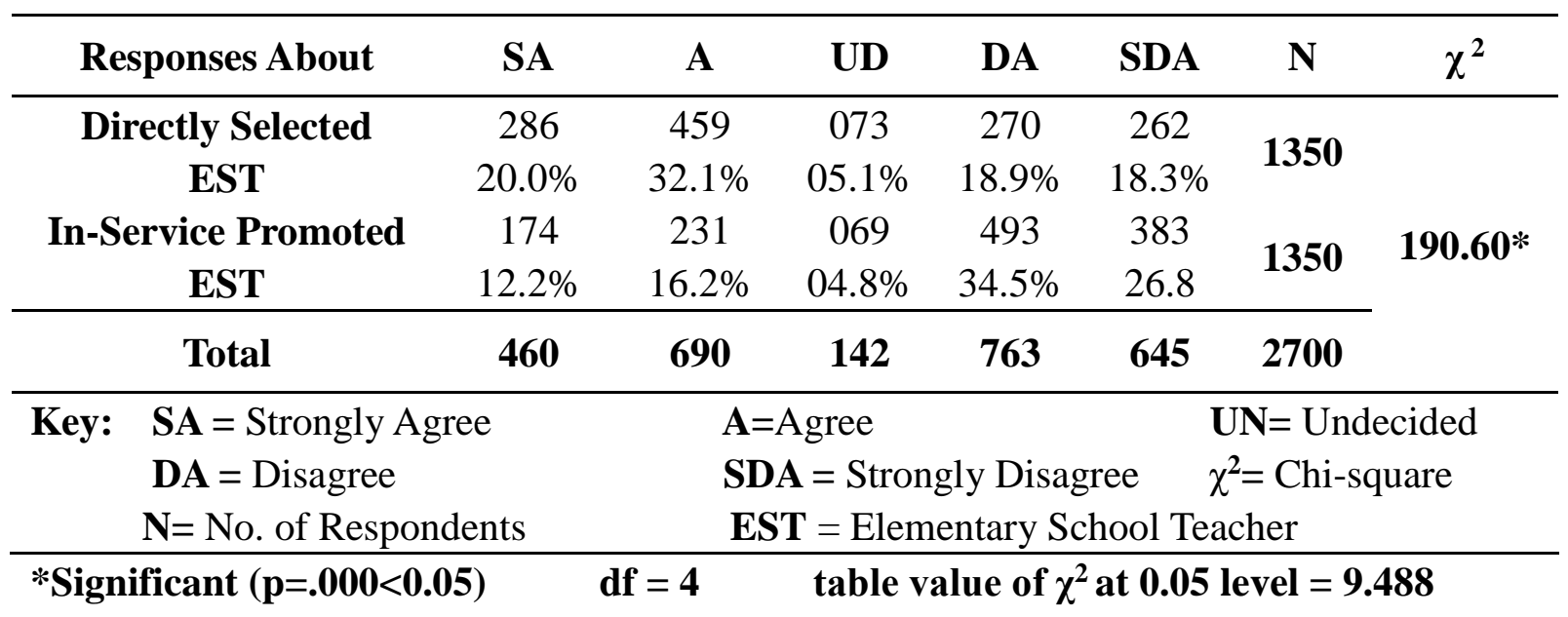




\section{Macrothink Institute ${ }^{T M}$}

Table 12 illustrates that the calculated value of $\chi^{2}$ was found to be 190.60 which is statistically significant $(\mathrm{p}<0.05)$ because it is greater than the table value of $\chi^{2}$ at 0.05 level. It indicates that students have different views about directly selected and in-service promoted elementary school teachers. They responded that majority of the directly selected elementary school teachers have the ability to manage student's seating arrangement properly whereas majority of the in-service promoted elementary school teachers do not have the ability to manage the same properly. It was further explained by the following bar graph:

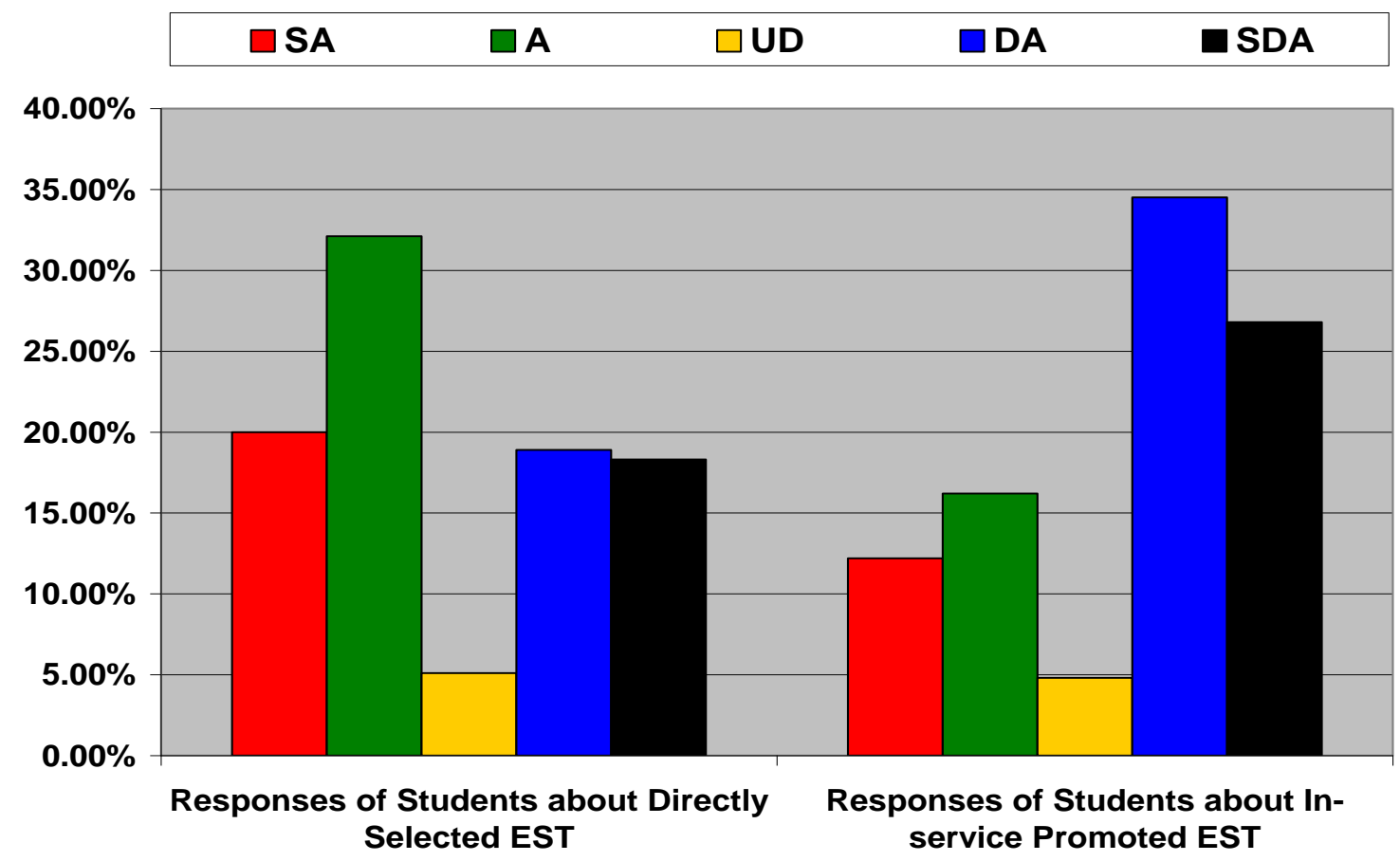

Fig 11: Showing the Responses of Students about In-Service Promoted and Directly Selected Elementary School Teachers

Findings and Conclusions

In the light of statistical analysis of data, the researchers arrived at the following conclusions:

1. Majority of the directly selected elementary school teachers formulate and announce classroom rules and regulations to ensure a favorable environment in side the classroom at the beginning of the session whereas majority of the in-service promoted elementary school teachers do not formulate and announce the same at the beginning of the session.

2. Majority of directly selected elementary school teachers have the ability to maintain discipline and control disruptive behavior of the students whereas majority of the in-service promoted elementary school teachers do not maintain discipline in classroom.

3. Majority of the directly selected elementary school teachers monitor undesired and offensive activities of the disruptive students constantly and properly whereas 
majority of the in-service promoted elementary school teachers do not monitor the same constantly and properly.

4. Majority of the directly selected elementary school teachers prevent students from disruptive behavior through moral, religious and motivational lectures whereas majority of the in-service promoted elementary school teachers do not prevent students from disruptive behavior through moral, religious and motivational lectures.

5. Both directly selected and in-service promoted elementary school teachers do not applies the principles of educational psychology in the classroom.

6. Majority of the directly selected elementary school teachers pay attention to students individually whereas majority of the in-service promoted elementary school teachers do not pay attention to students individually.

7. Both directly selected and in-service promoted elementary school teachers do not use educational technology/audio visual aids during instructional process.

8. Majority of the directly selected elementary school teachers try to enhance student's attitudes, behavior and academic performance whereas in-service promoted elementary school teachers do not try to enhance student's attitudes, behavior and academic performance.

9. Majority of the directly selected elementary school teachers keep in mind student's individual differences while teaching in the classroom whereas majority of the in-service promoted elementary school teachers do not keep in mind student's individual differences during instructional process.

10. Majority of the directly selected elementary school teachers pay proper attention on cleanliness in the classroom whereas in-service promoted elementary school teachers do not pay their attention on cleanliness in the classroom.

11. Majority of the directly selected elementary school teachers manage student's seating arrangement properly whereas majority of the in-service promoted elementary school teachers do not manage student's seating arrangement properly.

\section{Strong Points of Directly Selected Elementary School Teachers Regarding Classroom Management:}

After analysis of the data, the researchers concluded that following are the strong points of the directly selected elementary school teachers regarding classroom management:

1. They formulate and announce classroom rules and regulations to ensure a favorable environment in side the classroom at the beginning of the session

2. They have the ability to maintain discipline and control the disruptive behaviour of the students.

3. They monitor undesired and offensive activities of the disruptive students constantly and properly.

4. They prevent students from disruptive behavior through moral, religious and motivational lectures.

5. They pay attention to students individually.

6. They use various teaching methods during instructional process. 
7. They try their best to enhance student's attitudes, behavior, and academic performance.

8. They keep in mind student's individual differences while teaching in the classroom.

9. They pay proper attention on cleanliness in the classroom.

10. They have the ability to manage student's seating arrangement properly.

\section{Weak Points of Directly Selected Elementary School Teachers Regarding Classroom Management:}

After analysis of the data, the researchers concluded that following weak points of the directly selected elementary school teachers regarding classroom management:

1. They do not apply the principles of educational psychology in the classroom to enhance the student's academic and moral performance.

2. They do not use educational technology/audio visual aids in teaching learning process.

\section{Weak Points of In-Service Promoted Elementary School Teachers Regarding Classroom Management:}

After analysis of the data, the researchers concluded that following are the weak points of in-service promoted elementary school teachers regarding classroom management:

1. They do not formulate and announce classroom rules and regulations to ensure a favorable environment in side the classroom at the beginning of the session

2. They do not have the ability to maintain discipline and control the disruptive behaviour of the students.

3. They do not monitor undesired and offensive activities of the disruptive students constantly and properly.

4. They prevent students from disruptive behavior through moral, religious and motivational lectures.

5. They do not pay attention to students individually.

6. They do not use various teaching methods during instructional process.

7. They do not try their best to enhance student's attitudes, behavior, and academic performance.

8. They do not keep in mind student's individual differences while teaching in the classroom.

9. They do not pay attention on cleanliness in the classroom.

10. They do not manage student's seating arrangement properly.

11. They do not apply the principles of educational psychology in the classroom to enhance the student's academic and moral performance.

12. They do not use educational technology/audio visual aids in teaching learning process.

\section{Concluding Remarks}

In nutshell, it is concluded that the overall performance of the directly selected elementary school teachers is better and highly appreciable regarding classroom management. On the 
other hand, the overall performance of the in-service promoted elementary school teachers is poor, unsatisfactory and objectionable.

\section{Recommendations}

Keeping in view the conclusions, the researchers make some recommendations which are described as under:

1. As we know that according to the contemporary service structure of teachers, $75 \%$ in-service PST teachers will be promoted to elementary school teachers which is a great threat to the quality of education at elementary level. Therefore, at least $75 \%$ appointments of the elementary school teachers should be selected through open merit, competitive and transparent examination in order to raise quality of education at elementary level.

2. Special criteria, rules and regulations should be made for the appointment of the in-service teachers as elementary school teachers. Elementary school teachers should have at least B.Ed and B.A qualifications.

3. As majority of the in-service promoted elementary school teachers are not competent in classroom management therefore, it is strongly recommended that special training should be given to the existing in-service promoted elementary school teachers in classroom management and teaching methods to equip them with the modern teaching methods and techniques so that they may perform their duties effectively.

4. It is also recommended that all elementary school teachers should prepare lesson plan regularly to ensure quality teaching.

5. As it was found that both directly selected and in-service promoted elementary school teachers do not use educational technology during instructional process. Poor availability and lack of training and skills are the main reasons therefore it is strongly recommended that all the elementary school teachers should be given a special training in the utilization of educational technology so that they may become able to utilize technology in their teaching effectively. In addition, educational technologies i.e. overhead projectors, multimedia, educational televisions, radios, DVD players, models etc should be provided to each school immediately.

6. At the beginning of new session or class, classroom management rules and regulations should be devised and announced so that students may understand the behaviour of a teacher.

7. It is strongly recommended that teachers should keep and maintain record of disruptive and aggressive students and it should be sent to their parents. In addition, a special meeting programme should be launched inside the schools to discuss on the same issues

8. For directly selected and in-service promoted elementary school teachers, a proper system of continuous evaluation may be made. The weak points of the elementary school teachers should be identified by the principals and senior staff and necessary measures should be taken for the improvement of these teachers.

9. In-service promoted elementary school teachers are directed to pay their attention especially on maintenance of discipline in the classroom to ensure effective teaching 
learning process. In addition, they are also advised to pay their attention on cleanliness, proper seating arrangement, utilization of the principles of psychology, student's academic and moral performance, and student's individual differences etc.

10. Surprising visits of the higher authorities should be ensured to asses the teaching performance of the elementary school teachers.

11. Proper annual inspection system should be institutionalized in order to evaluate the teaching performance of elementary school teachers.

12. In-service training may be provided to all in-service promoted elementary school teachers on professional skills at least once in year to enable them to perform their duties effectively.

13. Special refresher courses should be arranged for in-service promoted elementary school teachers to increase their teaching efficiency and productivity.

\section{Recommendations for Future Research Studies}

1. It is recommended that this type of research study should be conducted in other districts and provinces.

2. It is also recommended that this type of research study should be conducted at secondary and higher secondary school level.

3. It is also recommended that this type of research study should be conducted to compare the competencies of female elementary school teachers regarding classroom management.

\section{References}

Bibi, S. (2005). Evaluation Study of Competencies of Secondary School Teachers in Punjab.

Ph.D Thesis, University Institute of Education \& Research, University of Arid Agriculture Rawalpindi, Pakistan. p. 10

Callahan, S. G. (1966). Successful Teaching in Secondary Schools. Foresman and Company, Atlanta. pp. 111-113

Dhand, H. (1990). Techniques of Teaching. Shish Publishing House, New Delhi, India. pp. 1-3.

Farris, G. P. (1996). Teaching: Bearing the Torch. Brown and Benchmark, London. UK.

Gay, L. R. (2005). Educational research: Competencies for analysis and application. Islamabad: National Book Foundation.

Kalra, A. (1997). Efficient School Management and Role of Principals. APH Publishing Corporation, New Delhi. pp. 10-21

Katozai, M. A. (2002). Preparation for the PCS screening Test of Senior English Teacher. University Publishers Shop \# 8-A Afghan Market, Qissa Khwani Peshawar. p. 119

Lang, R. H. \& Hebert, J. (1995). Teaching Strategies and Methods for Students Centered Instruction. America: Whiney, H.M.

Masrur, R. (2003). Thesis writing: A systematic approach. Islamabad: Allama Iqbal Open University.

Moskowitz, G., \& Hayman, J. L. (1976). Success strategies of inner-city teachers: A year-long 
study. Journal of Educational Research, 69, 283-289.

Nitsaisook, M. and Anderson, W. L. (1989). An Experimental Investigation of the Effectiveness of In-Service Teacher Education in Thailand, Department of Teacher Education, Ministry of Education, Bangkok. p.41

Sadker, P. M. \& Sadker D. M. (1997). Teachers School and Society. The McGraw-Hill Companies, Inc., New York, USA.

Sprinthall, A. N., Sprinthall, R. C., \& Oja, S. A. (1994). Educational Psychology, McGraw-Hill, Inc., New York, USA.

Walberg, J. H. (1987). Psychological Environment. In. M. J. Dunkin (Ed). The International Encyclopedia of Teaching and Teacher Education, Pergamon Press, Oxford, London, UK. p.553.

Website Used:

$\underline{\text { http://en.wikipedia.org/wiki/Classroom_management }}$ 